\title{
Two-Phase Flow Boiling in a Single Layer of Future High-Performance 3D Stacked Computer Chips
}

\author{
Sylwia Szczukiewicz, Navid Borhani, John Richard Thome \\ Laboratory of Heat and Mass Transfer (LTCM) \\ École Polytechnique Fédérale de Lausanne (EPFL) \\ EPFL STI IGM LTCM, ME G1 464, Station 9 \\ Lausanne, CH-1015, Switzerland \\ Phone: (+41) 216935981 \\ Fax: (+41) 216935960 \\ Email: john.thome@epfl.ch \\ Web page: http://ltcm.epfl.ch/
}

\begin{abstract}
The present study focuses on an experimental investigation of two-phase flow boiling in a silicon multi-microchannel evaporator, which emulates a single layer of a 3D stacked computer chip. The micro-evaporator is comprised of 67 parallel channels, each having a $100 \times 100 \mu \mathrm{m}^{2}$ cross-section area, and separated by $50 \mu \mathrm{m}$-wide fins. Two aluminium micro-heaters were sputtered onto the backside of the test section to provide two $0.5 \mathrm{~cm}^{2}$ heated areas in order to simulate the power dissipated by active component in $3 \mathrm{D}$ CMOS chips. The experiments were performed with a second identical test section having $50 \mu \mathrm{m}$-wide, $100 \mu \mathrm{m}$-deep, and $100 \mu \mathrm{m}$-long restrictions (micro-orifices) at the inlet of each channel to stabilize the two-phase flow. The goal of this experimental campaign was to perform simultaneous highspeed flow visualization and infra-red measurements of the two-phase flow and heat transfer dynamics across the entire micro-evaporator area. Refrigerants R245fa, R236fa and $\mathrm{R} 1234 \mathrm{ze}(\mathrm{E})$ were chosen as the working fluids. The microorifices successfully suppressed back flow, eliminated flow instabilities, provided a good flow distribution, and started the boiling process with some flashed vapor. Thermal performance was found to be uniform widthwise using these orifices.
\end{abstract}

KEY WORDS: chip, cooling, silicon, evaporator, multimicrochannels, two-phase, refrigerant, infra-red, high-speed, visualization

\section{NOMENCLATURE}

$B \quad$ heater width, $\mathrm{m}$

$D_{h} \quad$ channel hydraulic diameter, $\mathrm{m}$

E heat emission, W

$G \quad$ mass flux, $\mathrm{kg} / \mathrm{m}^{2} \mathrm{~s}$

$H \quad$ depth, m

I current, A

$L \quad$ length, $\mathrm{m}$

$M \quad$ mass flow rate, $\mathrm{kg} / \mathrm{s}$

$N$ number of channels, -

$N u_{z} \quad$ Nusselt number, -

Re Reynolds number, -

$S \quad$ infra-red camera sensing signal, -

$T$ temperature, ${ }^{\mathrm{O}} \mathrm{C}$

$\begin{array}{ll}V & \text { voltage drop across the heater, } \mathrm{V} \\ W & \text { width, } \mathrm{m} \\ d & \text { thickness, } \mathrm{m} \\ e & \text { expansion ratio, - } \\ f & \text { Fanning friction factor, - } \\ h & \text { enthalpy, } \mathrm{J} / \mathrm{kg} \\ k & \text { thermal conductivity, } \mathrm{W} / \mathrm{mK} \\ p & \text { pressure, } \mathrm{Pa} \\ q & \text { heat flux, } \mathrm{W} / \mathrm{m}^{2} \\ x & \text { vapor quality, - } \\ y & \text { direction perpendicular to the flow direction, } \mathrm{m} \\ z & \text { distance from the channel entrance, } \mathrm{m}\end{array}$

\section{Greek symbols}

$\Delta T_{\text {sub,in }}$ inlet liquid subcooling, $\mathrm{K}$

$\alpha$ heat transfer coefficient, $\mathrm{W} / \mathrm{m}^{2} \mathrm{~K}$

$\varepsilon \quad$ emissivity, -

$\eta \quad$ fin efficiency, -

$\rho$ mass density, $\mathrm{kg} / \mathrm{m}^{3}$

$\varphi \quad$ heat flux ratio, -

$\xi \quad$ singular pressure loss coefficient, -

\section{Subscripts}

amb ambient

ave average

$b$ base

ch channel

end end

$f$ fin

$f l \quad$ fluid

fr frictional

$h$ heater

in inlet

IR infra-red

$l \quad$ liquid

ld load

$m f$ manifold

out outlet

px pyrex

rad radiation

ref reference

rest restriction

si silicon

sg singular 


$\begin{array}{ll}\text { tape } & \text { tape } \\ \text { total } & \text { total } \\ v & \text { vapor } \\ w & \text { wall }\end{array}$

\section{INTRODUCTION}

3D integrated circuit stacked architectures with interlayer cooling, where the channels necessarily require a low aspect ratio and a size of $100 \mu \mathrm{m}$ or even smaller, are becoming very important for the micro-electronics industry due to the tremendous challenge of removing the continuously increasing heat fluxes dissipated by CPUs. In such systems, the layers are connected using through-silicon vias (TSVs), which reduce the distance for transporting data from one chip to another, making the process faster and generating less Joule heating. Hence, 3D integration of microprocessors offers an opportunity to continue the CMOS performance trends over the next decades and is an active area of current research [1, 2]. However, the difficulties and costs in designing and fabricating such 3D systems do not allow sufficient devices to be tested in order to determine their optimal geometries and operation. Therefore, there is a need to accurately measure the performance of the individual layers beforehand. As a result of this, the present research aims to investigate a single layer of a future high-performance 3D stack of computer chips whose eventual functionality per unit volume will nearly parallel the functional density of a human brain [3]. Due to a high-level system integration, air-cooling technology is inadequate for heat removal in 3D chips. Thus, the multi-microchannel twophase refrigerant evaporation has been proposed as a promising solution for electronics cooling [4] and is the focus of this research.

\section{EXPERIMENTAL SET-UP}

\section{Flow boiling test facility}

Figure 1 shows a schematic of the flow boiling test facility containing a closed loop of refrigerant driven by an oil-free micro-pump coupled with a frequency controller to set the desired liquid flow rate. A Coriolis mass flow meter is utilized to measure the flow rate with an accuracy of $\pm 0.35 \%$ of the reading. Downstream of the flow meter, there are a preheater/subcooler and an electrical pre-heater to set the desired inlet condition. The test section is a silicon multi-channel micro-evaporator described in the following subsection. The flow boiling test facility is equipped with two independent power supplies to apply direct DC current to the pre-heater and the test section. The voltage and current measurements are done via the National Instrument (NI) data acquisition system at a sampling rate of $1 \mathrm{kHz}$ over 1 minute and then averaged.

The test section's manifold is used to provide and remove fluid from the test section via the inlet and outlet manifold's plenums. Moreover, it provides optical access to both the top and the bottom surfaces of the test section. The refrigerant temperature is measured at 8 locations in the refrigerant circuit using $0.25 \mathrm{~mm}$ Thermocoax K-type thermocouples, which were calibrated within an accuracy of $\pm 0.1{ }^{\circ} \mathrm{C}$. Absolute pressures are measured by 10 bar pressure transducers with a full-scale accuracy of $\pm 0.1 \%$. A differential pressure sensor gives the pressure drop between the inlet and outlet manifold's plenums with a $\pm 0.023 \%$ accuracy of full-scale reading. After the fluid passes the test section, it is condensed and subcooled in a tube-in-tube type heat exchanger. The required fluid saturation temperature is maintained by adjusting the temperature of the Lauda chiller thermal bath liquid solution.

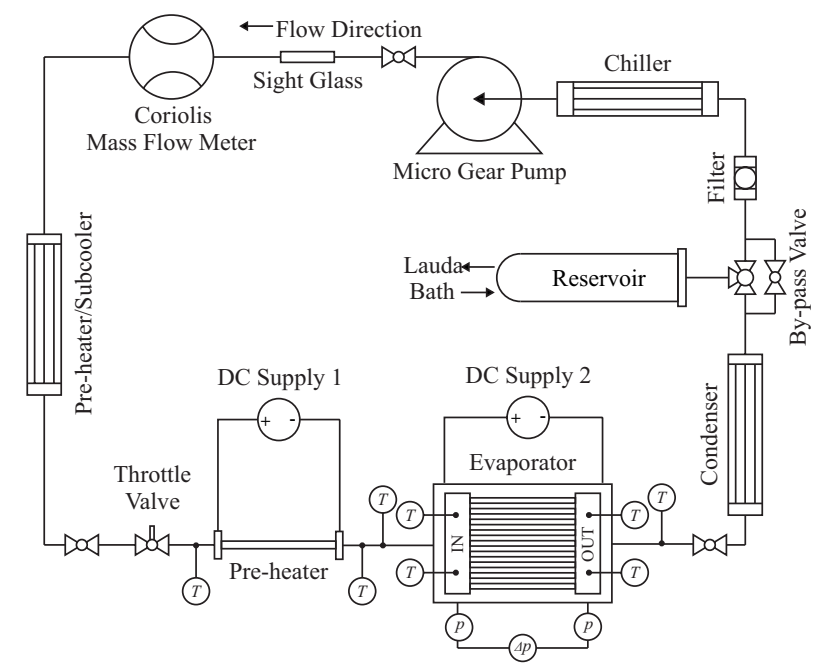

Fig. 1 Schematic of the flow boiling test facility.

An optical system, which comprises a high-speed video camera and an infra-red (IR) camera, is attached to the facility to simultaneously observe the two-phase diabatic flow and heat transfer dynamics in the silicon multi-microchannels. A Photron Fastcam-Ultima APX camera is placed above the test section, and a ThermaCAM SC3000 high-speed IR camera below. In order to minimize the effects of reflection, emissivity, viewing angle, etc., a novel in-situ pixel-by-pixel technique was developed to calibrate the raw IR images. The calibration under adiabatic conditions was performed with the flow loop by running single-phase flow of R245fa at the nearly maximum speed of the pump to assure uniform temperature distribution among the channels. The IR camera pixel array values were then calibrated over the range of 10 to $60{ }^{\circ} \mathrm{C}$ of the reference temperature, $T_{\text {ref }}$, with about $5{ }^{\circ} \mathrm{C}$ temperature steps. The reference temperature is an average of the inlet and outlet manifold's plenum temperatures. An example of the calibration curve is shown in Fig. 2. In the range of the two-phase flow experiments, the present IR temperature measurements are accurate to within $\pm 0.2{ }^{\circ} \mathrm{C}$, which provides a tenfold accuracy improvement compared to the value of $\pm 2{ }^{\circ} \mathrm{C}$ given by the manufacturer.

\section{Multi-microchannel evaporator}

The test section contains 67 parallel, $10 \mathrm{~mm}$-long microchannels having $100 \times 100 \mu \mathrm{m}^{2}$ cross-section areas and separated by $50 \mu \mathrm{m}$-wide fins. A diagram is shown in [3]. The channels were etched in a $380 \mu$ m-thick double-side polished silicon wafer applying a Deep Reactive Ion Etching (DRIE) process. Afterwards, the silicon die was anodically bonded to a $525 \mu \mathrm{m}$-thick transparent pyrex cover plate. The fluid enters the test section via a $1 \mathrm{~mm}$-wide inlet and leaves via a $2 \mathrm{~mm}$ wide outlet slit. Optical phase shifting and white light vertical scanning interferometry measurement of internal surface roughness of the channels gave a root mean square of $90 \mathrm{~nm}$. 
Two $1.5 \mu \mathrm{m}$-thick independent serpentine microheaters, made of aluminium, providing very good temperature uniformity were sputtered onto the backside of the micro-evaporator to mimic the power dissipated by active component in a 3D CMOS chip. Additionally, there are 4 resistance temperature detectors (RTDs), whose calibrations were done in the same way as the IR camera calibration. The DC current is applied via a HSEC8-130-010SDV-A edge connector (SAMTEC) soldered to the PCB board. The micro-evaporator base was covered with a high-emissivity black matt tape $\left(\varepsilon_{\text {tape }}\right.$ is in the vicinity of 1.0 within the present temperature range) in order to improve the accuracy of non-intrusive IR temperature measurements and to minimize the IR transmissivity of the test section, as suggested by $[5,6]$.

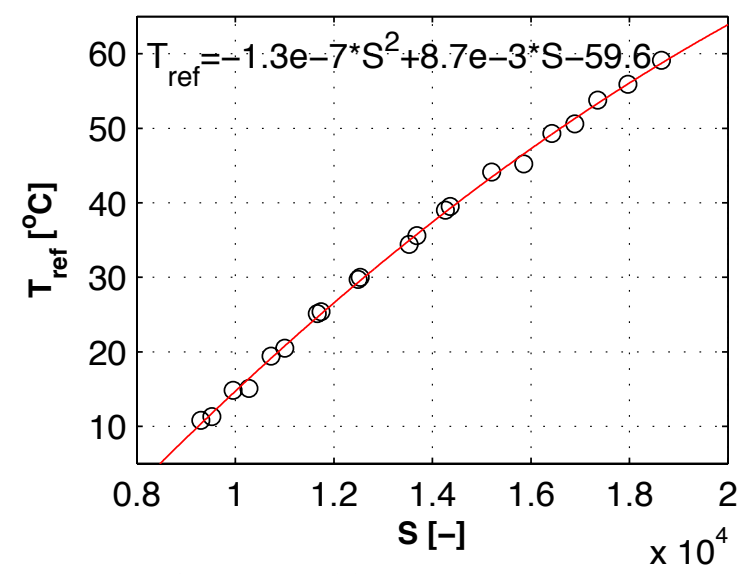

Fig. 2 Infra-red camera calibration curve.

Figure 3 presents two snapshots of the high-speed videos of flow visualization performed during the two-phase flow boiling of R245fa in the $100 \times 100 \mu \mathrm{m}^{2}$ cross-section area microchannels with and without the inlet micro-orifices. As indicated, significant flow instabilities, back flow, and nonuniformity of flow among the channels leading to highamplitude and high-frequency temperature and pressure oscillations [7], were present in the micro-evaporator without any inlet restrictions (micro-orifices). Then, such phenomena were prevented by designing the $50 \mu \mathrm{m}$-wide, $100 \mu \mathrm{m}$-deep and $100 \mu \mathrm{m}$-long restrictions at the inlet of each channel, as suggested by [8]. Moreover, the experiments for the microevaporator without any orifices resulted in the test section's failure before the tests were successfully accomplished.

\section{DATA REDUCTION}

Assuming uniformity of the flow, the mass flux flowing through one channel is calculated based on Eq. (1).

$$
G_{c h}=\frac{M}{N W_{c h} H_{c h}}
$$

The total pressure drop is measured in between the inlet and outlet manifold's plenums and is given as follows $[9,10]$ : $\Delta p_{\text {total }}=\Delta p_{f r}+\Delta p_{s g}$

The single-phase frictional pressure drop along the channel is determined based on Eq. (3), where $f$ is the Fanning friction factor for developing flow.

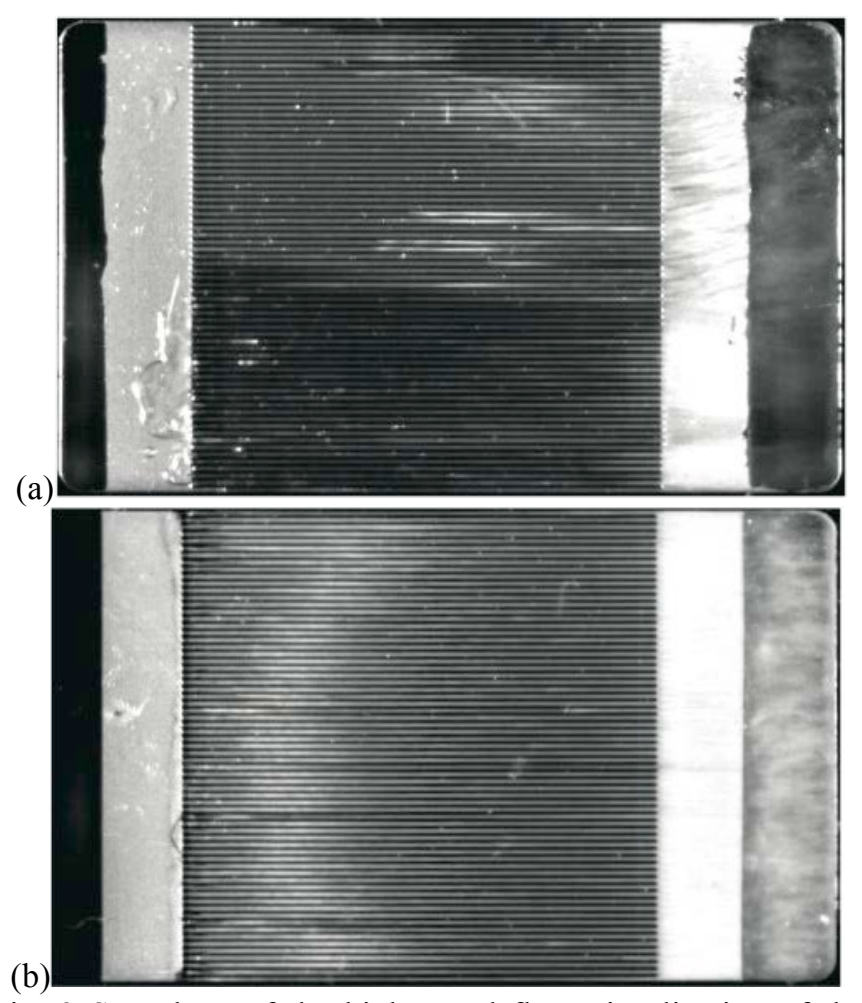

Fig. 3 Snapshots of the high-speed flow visualization of the two-phase flow boiling of R245fa for $G_{c h}=2^{\prime} 035$ $\mathrm{kg} / \mathrm{m}^{2} \mathrm{~s}, \quad q_{b}=36.5 \mathrm{~W} / \mathrm{cm}^{2}$ in the multi-microchannel evaporator: (a) without any inlet restrictions, and (b) with the $50 \mu \mathrm{m}$-wide, $100 \mu \mathrm{m}$-deep, and $100 \mu \mathrm{m}$-long inlet micro-orifices.

$\Delta p_{f r}=4 f \frac{G_{c h}^{2}}{2 \rho_{l}} \frac{L_{c h}}{D_{h}}$

In order to evaluate the Fanning friction factor and the adiabatic single-phase frictional pressure drop along the channel, a 3D numerical simulation using Ansys FLUENT version 12.1.2 was performed for a single channel with the micro-orifice at the channel inlet considering symmetry in the lateral direction. The grid of 3'216'000 cubic elements (2.5 $\mu \mathrm{m}$ in each direction), ensuring grid independence of the simulation's results, was employed. Uniform constant velocity and outlet pressure were set as the inlet and outlet boundary conditions, respectively. Moreover, no-slip wall boundary condition was used for the other boundaries except for the symmetry plane where a symmetry boundary condition was applied. The physical properties of the fluid were evaluated using the average of the inlet and outlet experimental temperatures. Good agreement was found comparing the numerical results with the Shah and London [11] formula for laminar developing flow in square channels with our aspect ratio of 1.0. However, the simulated values were slightly higher due to the fact that inlet restrictions were not considered in the formula proposed by Shah and London [11]. Afterwards, the singular pressure drop due to the flow contraction in the test section's inlet before micro-orifice and the flow expansion in the test section's outlet was calculated based on Eq. (2) by subtracting the simulated frictional pressure drop from the total experimentally measured pressure 
drop. Figure 4 shows a curve fitting of the computed values to the well-known formula of Idelcik [12] obtained for R236fa. In the end, Eq. (2) was modified as follows:

$$
\Delta p_{\text {total }}=\Delta p_{f r}+\Delta p_{s g}+\Delta p_{m f}
$$

where $p_{m f}$ is the pressure drop in the test section's.

(a)
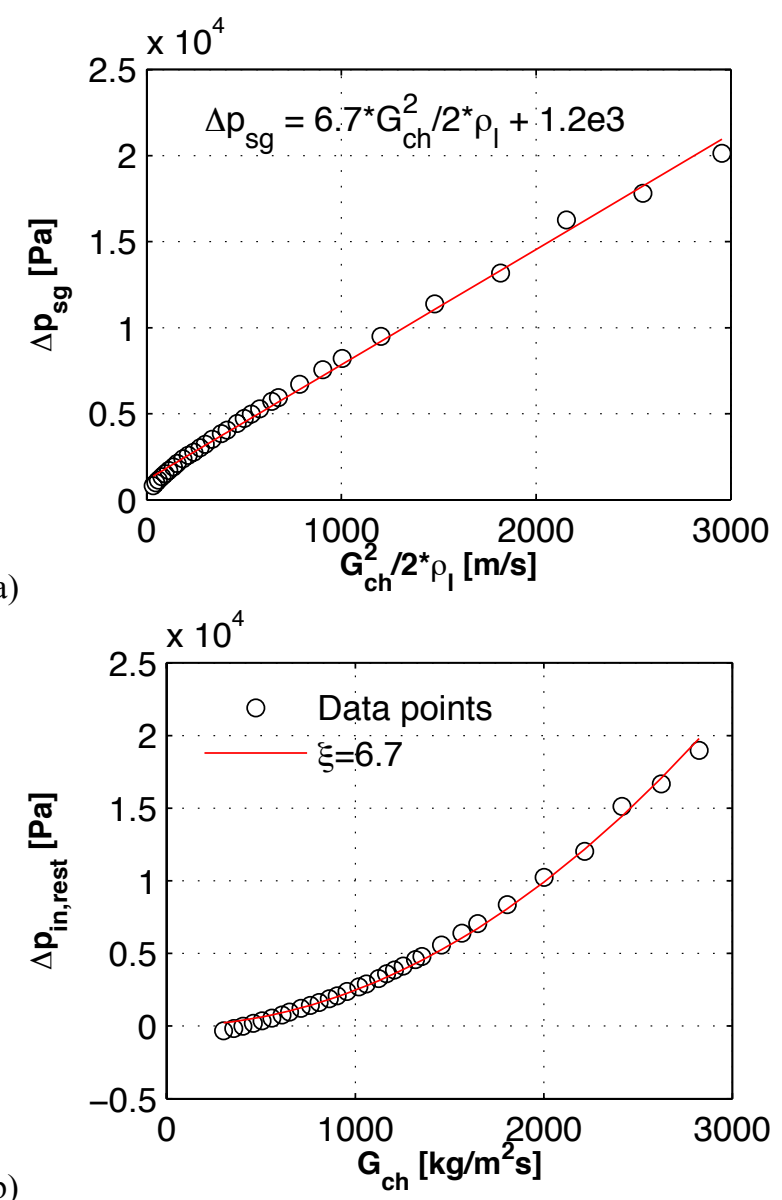

Fig. 4 Examples of: (a) curve fitting to the Idelcik formula [12], and (b) single-phase inlet restriction pressure losses obtained for R236fa.

The diabatic two-phase channel pressure drop is obtained, as described in [13] accounting for the inlet, $p_{\text {in,rest }}$, and the outlet restriction pressure losses, $p_{\text {out,rest }}$. The outlet restriction pressure losses, correlated based on the outlet conditions, might be extended to the uniform heat flux experiments assuming that the two-phase flow pattern does not affect the pressure drop results. Therefore, it stands that:

$\Delta p_{\text {out }, \text { rest }}=p_{\text {ch, end }}-p_{\text {out }}$

where: $p_{c h, e n d}$ is evaluated based on the vapor pressure curve at the lateral average value of the infra-red temperature measurements, and $p_{\text {out }}$ is the absolute pressure measured in the manifold's outlet plenum. In order to determine $p_{c h \text {,end, the }}$ power is applied only to the first heater, thus giving two-phase adiabatic flow of known vapor quality at the end of the channels. The measurement is performed once the operational steady-state condition is reached. The local base temperature measurements at the outlet of the channels could be assumed to be the local saturation temperatures, if the channel ends are not affected by the conjugate effect, which was ensured by plotting the spatial derivatives of the temperature along the center line in the flow direction for a vast array of the experimental test conditions. The temperatures along the width of the test section are very uniform, illustrating the good thermal characteristic of the test section's design.

The inlet liquid subcooling is calculated based on:

$$
\Delta T_{\text {in }, \text { sub }}=T_{\text {sat }}\left(p_{\text {in }}\right)-T_{\text {in }}
$$

where the fluid saturation temperature is obtained from the vapor pressure curve at the $p_{\text {in }}$ and the $T_{i n}$ is the average of the temperature measured by two thermocouples installed at the inlet manifold's plenum.

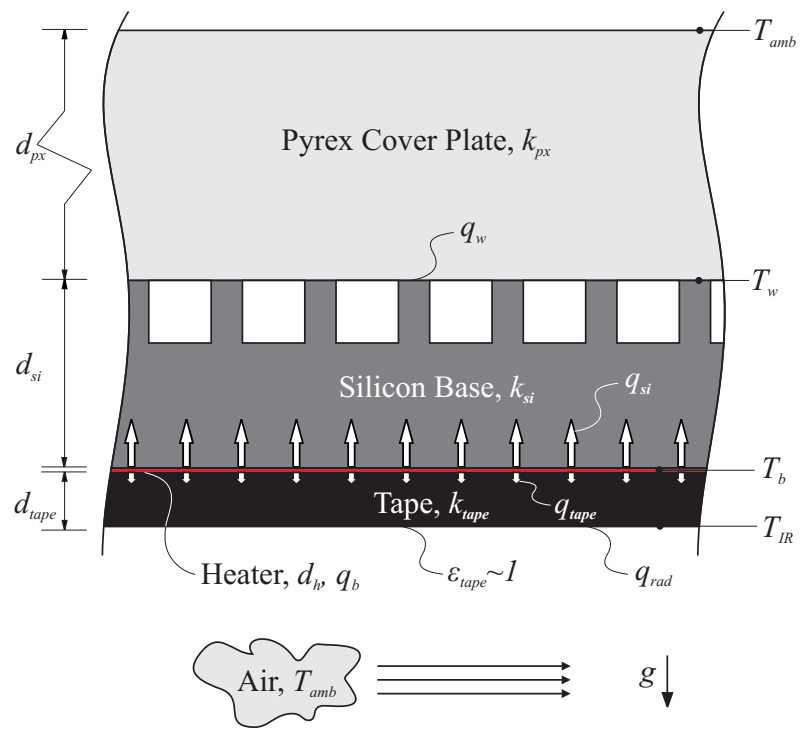

Fig. 5 Schematic of the test section.

The heat flux produced by the heater is given as follows:

$q_{l d}=\frac{I V}{L_{h} B}$

The base heat flux, $q_{b}$, is calculated accounting for the heat loss:

$q_{b}=\varphi \frac{I V}{L_{h} B}=q_{s i}+q_{\text {tape }}$

where $\varphi$ takes into account the voltage drop down the wiring between the heater and the power supply assuming the resistivity of the heater to be constant over the temperature range of the two-phase experiments. As shown in Fig. 5, the base heat flux is the sum of the heat transferred to the silicon base and to the tape. The $q_{\text {tape }}$ is considered to be equal to the $q_{\text {rad }}$, which is determined based on the Stefan-Boltzmann's law for a black body exposed to the surrounding of known temperature, $T_{a m b}$, since $\varepsilon_{\text {tape }}$ is in vicinity of 1.0 in the present temperature range. The maximum value of heat emission by radiation, $E_{\text {rad }}$, was $0.023 \mathrm{~W}$, which corresponds to the temperature drop through the tape on an order of magnitude smaller than the IR camera's measurement accuracy. Therefore, the temperature gradient in the tape is neglected and the temperature observed by the IR camera is assumed to be the test section base temperature. In order to check this assumption, various single-phase energy balance tests were 
run for different mass fluxes, heat fluxes and inlet liquid subcoolings.

The local vapor quality is calculated using an energy balance of the test section, where the net power supplied to the device and the mass flow rate are known:

$x(z)=\frac{q_{s i} B}{M h_{l v}} z+\frac{h_{l, \text { in }}(z)-h_{l, \text { out }}(z)}{h_{l v}}$

The local wall heat transfer coefficient is estimated based on:

$$
\alpha_{w}(z)=\frac{q_{w}}{T_{w}(z)-T_{f l}(z)}
$$

where the wall heat flux, $q_{w}$, is calculated using the fin efficiency formula for $(N-1)$ parallel rectangular fins:

$q_{w}=q_{s i} \frac{N\left(W_{f}+W_{c h}\right)-W_{f}}{2(N-1)\left(H_{c h}+0.5 W_{f}\right) \eta+N W_{c h}}$

where

$$
\begin{aligned}
& \eta=\frac{\tanh \left(m\left(H_{c h}+0.5 W_{f}\right)\right)}{m\left(H_{c h}+0.5 W_{f}\right)} \\
& m=\sqrt{\frac{2 \alpha_{w}\left(L_{c h}+W_{f}\right)}{W_{f} L_{c h} k_{s i}}}
\end{aligned}
$$

The change of the base temperature in the lateral direction is neglected assuming that the heat transfer rate is uniform over the fin surface. Equations (10) to (13) are interdependent, thus, they are iteratively solved with a fixed-point method. The wall temperature is determined using infra-red thermography as follows:

$$
T_{w}=T_{b}-\frac{q_{s i} d_{s i}}{k_{s i}}=T_{I R}+\frac{q_{\text {tape }} d_{\text {tape }}}{k_{\text {tape }}}-\frac{q_{s i} d_{s i}}{k_{s i}}
$$

where the thermal conductivity of silicon, $k_{s i}$, was evaluated based on a curve fitting to the experimental data of Shanks et al. [14] and the tape thermal conductivity, $k_{\text {tape }}$, was measured experimentally by carrying out some steady-state thermal conductivity measurements within the temperature range between 20 and $60{ }^{\circ} \mathrm{C}$. As explained above, the temperature gradient through the tape is neglected.

\section{OPERATIONAL CONDITIONS AND PRE-VALIDATION TESTS}

Three refrigerants, namely R245fa, R236fa (low-pressure refrigerants), and $\mathrm{R} 1234 \mathrm{ze}(\mathrm{E})$ (medium-pressure refrigerant) were tested. The properties of the fluids were obtained with the REFPROP 8.0 software based on the NIST Standard Reference Database 23. The test conditions, as well as uncertainties calculated using the method of Kline and McClintock [15], are presented in Table 1. A wide range of pressures was tested, which demonstrated the very good quality of the anodic bonds. Once the desired saturation temperature was reached, the mass velocity was set by coupling a frequency controller with a micropump. The inlet liquid subcooling, $\Delta T_{\text {sub,in }}$, was controlled by means of either the pre-heater/subcooler or the electrical pre-heater. After reaching steady-state at each step, heat flux was applied to the test section to initiate the evaporation in the channels. Then, for a specified heat flux, the mass flux was gradually

\begin{tabular}{|c|c|c|}
\hline Parameter & Value & Uncertainty \\
\hline$N,-$ & 67 & - \\
\hline$L_{h}, \mu \mathrm{m}$ & $9 ’ 765$ & \pm 5 \\
\hline$B, \mu \mathrm{m}$ & $10^{\prime} 000$ & \pm 5 \\
\hline$H_{c h}, \mu \mathrm{m}$ & 100 & \pm 5 \\
\hline$W_{c h}, \mu \mathrm{m}$ & 100 & \pm 5 \\
\hline$W_{f}, \mu \mathrm{m}$ & 50 & \pm 5 \\
\hline$d_{s i}, \mu \mathrm{m}$ & 380 & \pm 10 \\
\hline$d_{g l}, \mu \mathrm{m}$ & 525 & \pm 10 \\
\hline$d_{h}, \mu \mathrm{m}$ & 1.5 & $\pm 5 \%$ \\
\hline$G_{c h}, \mathrm{~kg} / \mathrm{m}^{2} \mathrm{~s}$ & $283-2 ’ 370$ & $30-8 \%$ \\
\hline$I, \mathrm{~A}$ & $3.99-20.56$ & $\pm 0.61 \%$ \\
\hline$V, \mathrm{~V}$ & $0.52-2.51$ & $\pm 0.53 \%$ \\
\hline$T_{I R},{ }^{\mathrm{O}} \mathrm{C}$ & $\begin{array}{l}31.2-57.1(\text { R245fa }) \\
30.4-50.3(\text { R236fa }) \\
29.9-43.1(\text { R1234ze(E)) }\end{array}$ & $\begin{array}{l} \pm 0.2 \\
\pm 0.2 \\
\pm 0.2\end{array}$ \\
\hline$T_{\text {sat,out }},{ }^{\mathrm{O}} \mathrm{C}$ & 31.5 & \pm 1 \\
\hline$\Delta T_{s u b, i n}, \mathrm{~K}$ & 5.7 & \pm 1.5 \\
\hline$p_{\text {sat,out }}$, bar & $1.84-6.04$ & $\pm 0.1 \% \mathrm{FS}$ \\
\hline$\Delta p_{\text {total }}, \mathrm{kPa}$ & $2-113$ & $\pm 0.023 \% \mathrm{FS}$ \\
\hline
\end{tabular}

increased. Time intervals of 30 minutes between every two data points were applied to all the test conditions.

Table 1. Experimental parameters and uncertainties.

In order to prove that the experimental facility is able to accurately measure some single-phase liquid heat transfer coefficients, the experimental Nusselt numbers were compared to the prediction method of the Shah and London [11] for laminar developing flow with a uniform heat flux boundary condition for R1234ze(E) at the channel location $z=5 \mathrm{~mm}$. As illustrated in Fig. 6a, good agreement was found. Some validation tests were carried out for the others refrigerants, R245fa and R236fa, at different longitudinal distances, such as $0.5 \mathrm{~mm}$ or $2 \mathrm{~mm}$ from the channel entrance. As a result, good agreement was revealed. High discrepancies were observed at low Reynolds numbers, below 400, due to the insufficient measurement accuracy and the fact that the experimental facility was built to carry out two-phase experiments.

The two-phase flow tests were performed above the ambient temperature, thus the heat transfer from the environment to the test section was neglected. The input power from the light source, used for flow visualization, was measured with the Laser Power Meter Spectra-Physics 407a and was always less than $1 \%$ of the heat flux applied to the test section by the heater, therefore, was neglected. Moreover, as shown in Fig. 6b, comparison of the local temperature measurements obtained with the IR camera for the base heat flux of $24.6 \mathrm{~W} / \mathrm{cm}^{2}$ and different mass fluxes with and without illumination revealed very good agreement. These two series of tests were done within the time period of 15 days, which proves good measurement reproducibility of the two-phase flow boiling experiments. The relative heat loss to the environment was assumed to be negligible, except for the low heat inputs. In those cases, the heat loss was estimated based on the single-phase energy balance of the test section. 


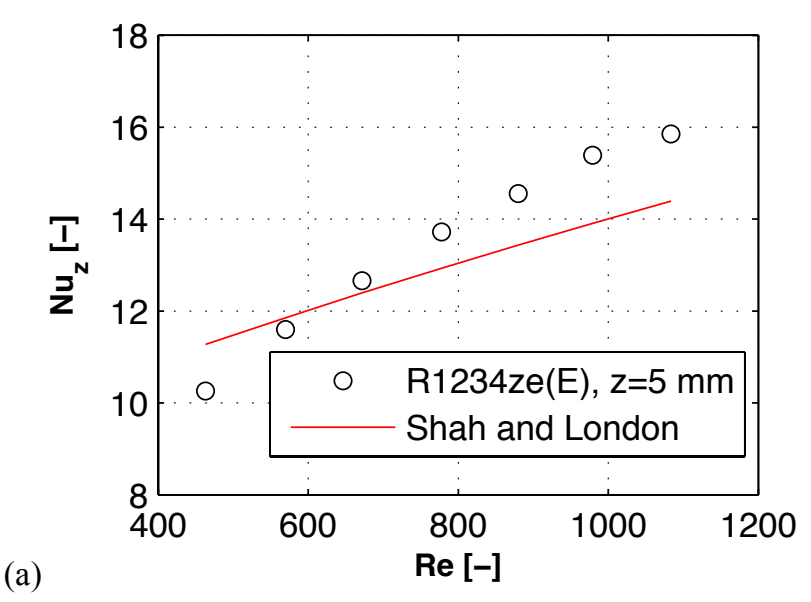

(a)

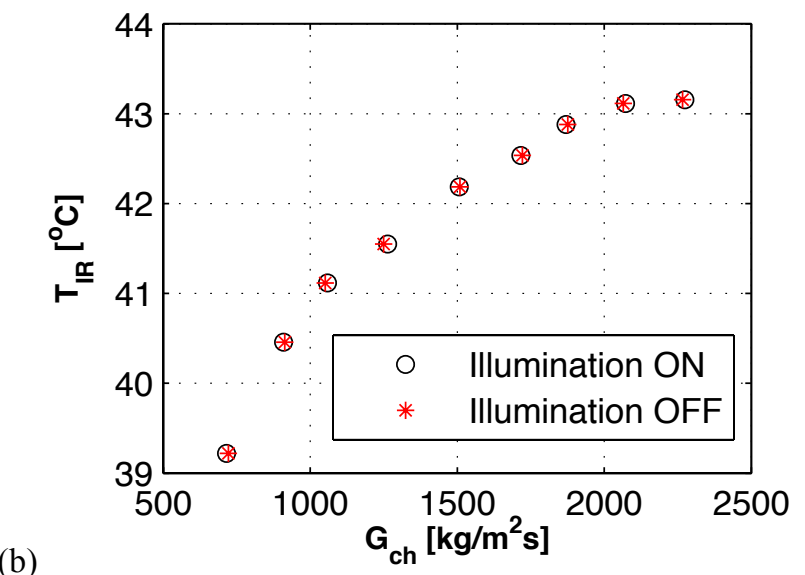

Fig. 6 (a) Pre-validation of the experimental test facility with the average Nusselt numbers predicted by the Shah and London [11] formula for laminar developing flow with uniform heat flux boundary condition, $z=5 \mathrm{~mm}$, R1234ze(E), and (b) local base temperature with and without illumination for the two-phase flow of R236fa for mass flux varying between 715 and $2,275 \mathrm{~kg} / \mathrm{m}^{2} \mathrm{~s}$ while dissipating the base heat flux of $24.6 \mathrm{~W} / \mathrm{cm}^{2}$.

\section{HIGH-SPEED FLOW AND TEMPERATURE DYNAMICS VISUALIZATIONS}

2D flow and temperature dynamics visualizations of the two-phase flow boiling over the entire micro-evaporator area were conducted as a part of this experimental investigation. The fluid flows from left to right in all of the presented images. High-speed flow visualization was carried out with the spatial resolution of 1'024 x 768 pixels at 2'000 fps over 4 second, with a field of view that includes the channels as well as the inlet and outlet test section's plenums and slits. The single-phase liquid in the channel near the entrance and the annular flow downstream in the channel are represented by the dark areas, where the two-phase flow mixture (bubbly and slug flows) appears brighter with a very shinny liquid-vapor interface, as illustrated in Fig. 7a. The dynamic temperature visualizations were performed by means of the high-speed IR camera with a spatial resolution of $320 \times 240$ pixels, out of which an array of $100 \times 100$ pixels covers the $1 \times 1 \mathrm{~cm}^{2}$ heated area of the micro-evaporator, at 60 fps over 1 minute. Therefore, 600'000 individual temperatures per second were recorded. One needs to remember that the temperature data were obtained through the in-situ pixel-by-pixel calibration of the IR camera.

(a)
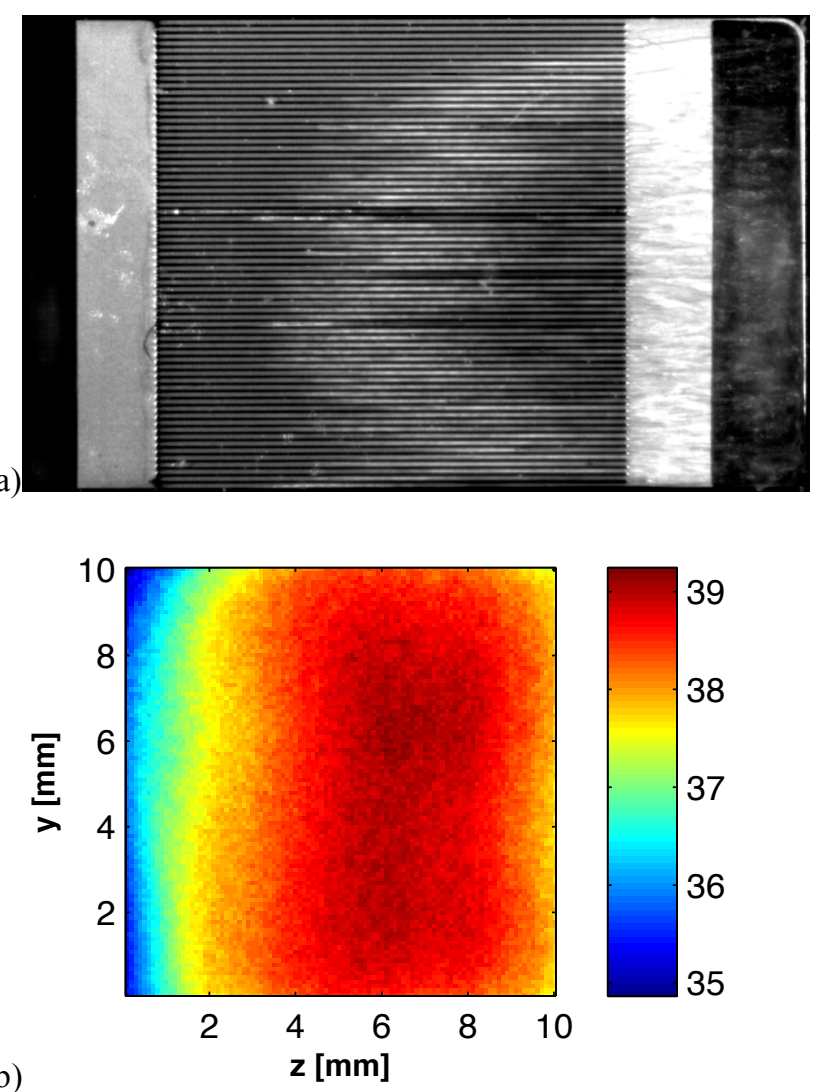

Fig. 7 (a) Flow and (b) temperature patterns of the two-phase flow of R236fa, $G_{c h}=1 ' 299 \mathrm{~kg} / \mathrm{m}^{2} \mathrm{~s}, q_{b}=13.5 \mathrm{~W} / \mathrm{cm}^{2}$.

The two-phase flow boiling tests performed for R245fa, $\mathrm{R} 236 \mathrm{fa}$, and R1234ze(E) in the micro-evaporator with the inlet restrictions were categorized in 8 operating regimes: (\#1) single-phase flow in the test section with the vapor bubbles at the manifold's outlet plenum, (\#2) single-phase flow followed by two-phase flow with back flow, (\#3) unstable two-phase flow with back flow developing into jet flow, (\#4) jet flow (two-phase flow is initiated only in few channels; vapor phase is push out of the channel creating a jet), (\#5) single-phase flow followed by two-phase without back flow (desirable operating regime), (\#6) two-phase flow with back flow triggered by bubbles formed in the flow loop before the test section, (\#7) flashing two-phase flow with back flow, and (\#8) flashing two-phase flow without back flow (most desirable operating regime). The numbers from $\# 1$ to $\# 8$ are further on used to refer to particular operating regimes.

For the lowest base heat flux, $1.9 \mathrm{~W} / \mathrm{cm}^{2}$, flow remains in single-phase flow regime in the micro-evaporator. However, for R245fa, in some conditions, bubbles are observed at the manifold's outlet plenum (operating regime \#1). The twophase flow in the microchannels, right after this occurs, is highly unstable with the vapor coming back to the manifold's and test section's inlet plenums. This phenomenon leads to temporal and spatial non-uniformity of the flow inside the channels (operating regimes \#2 and \#3) and back flow in some 
cases (operating regimes \#2, \#3 and \#7). The amount of vapor coming back to the inlet manifold's plenum reduces as soon as the mass flow rate is increased while the heat flux is kept constant. The back flow is suppressed by the inlet restrictions (operating regime \#5). As shown in Fig. 7a, the transition to the two-phase flow does not happen at the same longitudinal positions in all the channels: while the flow in the upper channels is still in single-phase flow regime, in the rest of the channels, the two-phase flow has already appeared. The reason for this is the heat spreading into the copper manifold, which consequently reduces the heat flux to the flow.

As the heat flux is further increased, flashing two-phase flow without back flow operating regime (\#8) is obtained, which is the most desired operating regime of the two-phase flow boiling in multi-microchannels. The flow and temperature patterns of this operating regime are presented in Fig. 8. The two-phase flow is initiated from the beginning of the channel in the form of bubbly flow, which then develops into slug and annular flows. Due to the flashing effect, the boiling starts at a lower heat flux [8], thus, the walltemperature distribution becomes more uniform and the walltemperature overshoot for the onset of boiling is circumvented.

(a)
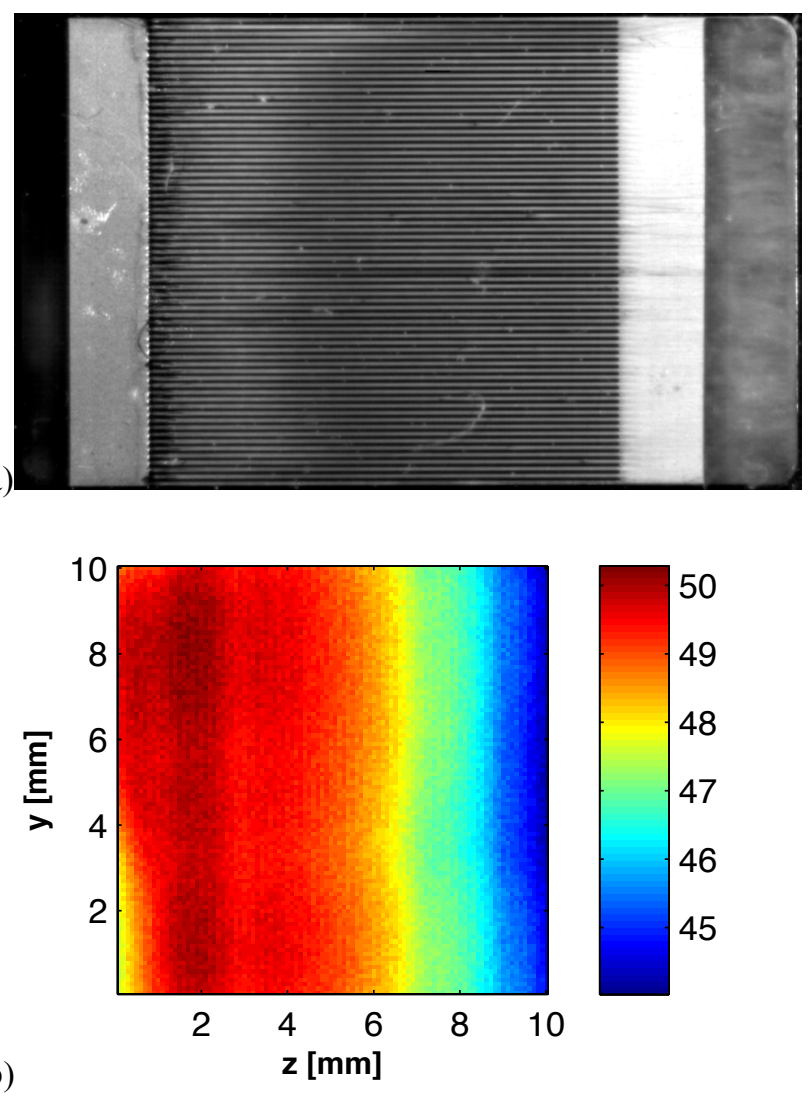

Fig. 8 (a) Flow and (b) temperature patterns of the two-phase flow of R236fa, $G_{c h}=2^{\prime} 299 \mathrm{~kg} / \mathrm{m}^{2} \mathrm{~s}, q_{b}=48.6 \mathrm{~W} / \mathrm{cm}^{2}$.

As found, the transitions from one regime to another were fluid-dependent. In general, the flow of R236fa was stable over a wider range of parameters and the transitions in between the operating regimes were more predictable in comparison to R245fa and R1234ze(E). The flashing two- phase flow operating regime for R236fa was observed for mass fluxes higher than $\sim 1^{\prime} 500 \mathrm{~kg} / \mathrm{m}^{2} \mathrm{~s}$ and base heat fluxes higher than $\sim 24 \mathrm{~W} / \mathrm{cm}^{2}$. For R245fa, there were only 6 data points recorded that showed the flashing two-phase flow without back flow, whereas for R1234ze(E), the two-phase flow was stable for mass fluxes higher than $\sim 900 \mathrm{~kg} / \mathrm{m}^{2} \mathrm{~s}$ and base heat fluxes higher than $\sim 32 \mathrm{~W} / \mathrm{cm}^{2}$.

For some of the experimental conditions, the vapor bubbles were formed before the test section due to the combined effects of fluid preheating and geometrical components in the flow loop. This phenomenon did not have any significant effect on the two-phase flow in the test section and the back flow observed in few cases (operating regime \#6) was not comparable to the one occurring in the operating regimes \#2, \#3 and \#7.

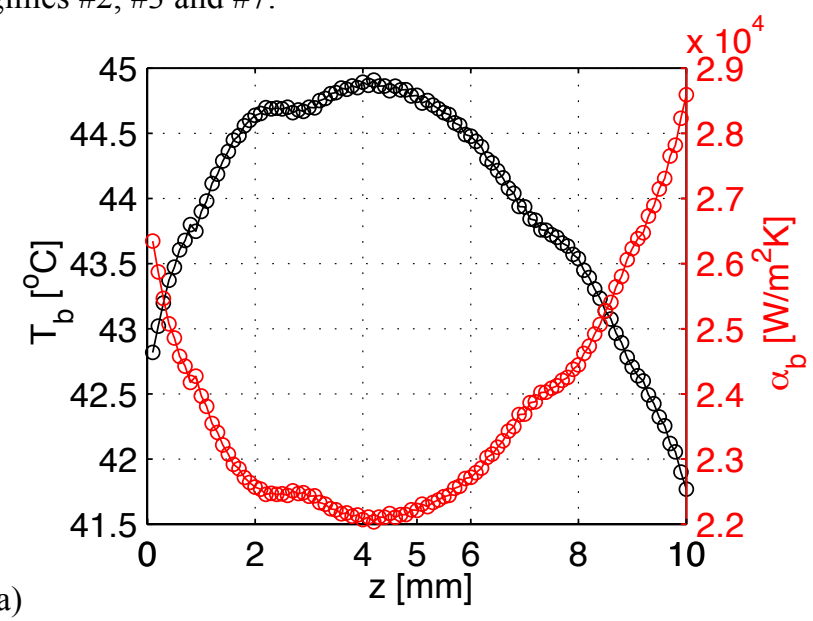

(a)

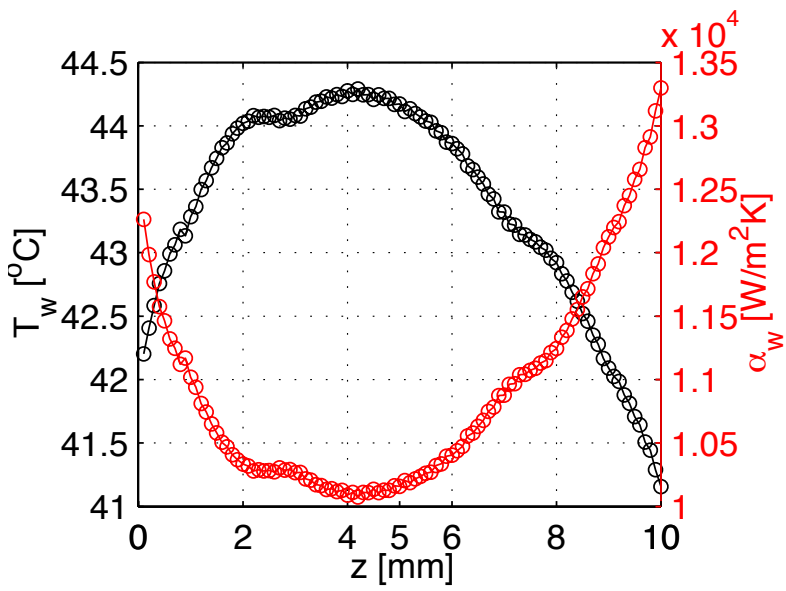

(b)

Fig. 9 (a) Test section base, and (b) wall temperatures and two-phase heat transfer coefficients of R236fa for $G_{c h}=27278 \mathrm{~kg} / \mathrm{m}^{2} \mathrm{~s}, q_{b}=29.2 \mathrm{~W} / \mathrm{cm}^{2}$ with total pressure drop from inlet to outlet of 0.65 bar.

\section{HEAT TRANSFER RESULTS}

A temperature map was calculated for every test condition by averaging the IR temperature measurements over 1 minute captured with a frequency of $60 \mathrm{~Hz}$. The data points of this map were then averaged in the lateral direction of the test section resulting in 100 points in the flow direction. The local time-averaged base and wall temperatures for the operating regime \#8, as well as the two-phase heat transfer coefficients, of R236fa for $G_{c h}=2 ’ 278 \mathrm{~kg} / \mathrm{m}^{2} \mathrm{~s}$ and $q_{b}=29.2 \mathrm{~W} / \mathrm{cm}^{2}$ are 
presented in Fig. 9. This operating regime is characterized by the best flow and thermal stabilities.

The IR temperature measurements over the entire microevaporator area were done with a standard deviation of \pm 0.3 ${ }^{\circ} \mathrm{C}$. The fluid temperature increased only $0.2{ }^{\circ} \mathrm{C}$ from the inlet to outlet manifold's plenums. The base heat transfer coefficients were used as the first assumption for iteratively calculating the wall heat transfer coefficients with a fixedpoint method. The characteristic U-shape of the heat transfer coefficient trend with the minimum shifted to the left side of the graph (entrance of the channel) can be seen. This trend can be explained by analyzing the flow patterns appearing in the channels and transitions in between them, particularly isolated to coalescing bubbles (IB-CB) and coalescing bubbles to annular flow (CB-A) transitions [16]. A high value of heat transfer coefficient at the beginning of the channel might be associated with the first bubbles initiated by the microorifices. The heat transfer coefficient started to decrease in the direction of the flow when the bubbles coalesce and local intermittent dry-out patches were formed, as described in the three-zone flow boiling model [17], and observed visually by [18]. The minimum value of the heat transfer coefficient fell at the location where the CB-A transition took place, which was found by means of flow visualization of the two-phase flow boiling in the micro-evaporator. As soon as the flow transitioned into the annular flow, the value of heat transfer coefficient started to increase.

\section{CONCLUSIONS}

Two silicon test sections, with and without inlet microorifices, both having $67100 \times 100 \mu \mathrm{m}^{2}$ channels, were tested as a promising solution for heat removal in future highperformance 3D stacked computer chips. The two-phase flow boiling in the micro-evaporator without any inlet restrictions was highly unstable in time and space. Thus, $50 \mu \mathrm{m}$-wide, 100 $\mu \mathrm{m}$-deep, and $100 \mu \mathrm{m}$-long inlet restrictions were applied to each channel in the second test section. The micro-orifices successfully suppressed back flow, eliminated flow instabilities, and considerably improved flow uniformity among the channels for relatively high heat fluxes and mass fluxes. Moreover, due to the flashing effect, the onset of boiling started at lower heat fluxes, so that the walltemperature distribution became more uniform and the walltemperature overshoot for the onset of boiling was significantly reduced. The two-phase flow boiling tests were performed over a wide range of pressures, exceeding a value of 6 bars. In the end, it might be concluded that the microorifices extended the lifetime of the test section, which is a vital issue for the future 3D interlayer cooling systems.

High-speed flow visualization and IR temperature measurements enabled the study of the two-phase flow boiling process in the multi-microchannel evaporator by taking both into account flow stability and heat transfer performance. Eight different operating regimes of the two-phase flow in the micro-evaporator with the $50 \mu \mathrm{m}$-wide, $100 \mu \mathrm{m}$-deep and 100 $\mu \mathrm{m}$-long inlet restrictions were distinguished: (\#1) singlephase flow in the test section with the vapor bubbles at the manifold's outlet plenum, (\#2) single-phase flow followed by two-phase flow with back flow, (\#3) unstable two-phase flow with back flow developing into jet flow, (\#4) jet flow, (\#5) single-phase flow followed by two-phase without back flow, (\#6) two-phase flow with back flow triggered by bubbles formed in the flow loop before the test section, (\#7) flashing two-phase flow with back flow, and (\#8) flashing two-phase flow without back flow, which is the most desired two-phase flow operating regime in multi-microchannels. The transitions from one regime to another were fluid-dependent. In general, the flow of R236fa was stable over a wider range of parameters and the transitions in between the operating regimes were more predictable in comparison to R245fa and R1234ze(E).

The junction temperature of the micro-evaporator with the inlet micro-orifices, TIR, was always kept below the temperature of $57.1{ }^{\circ} \mathrm{C}$ for R245fa, $50.3{ }^{\circ} \mathrm{C}$ for R236fa, and the most importantly $43.1{ }^{\circ} \mathrm{C}$ for R1234ze(E), which is lower than the given temperature limit of $85{ }^{\circ} \mathrm{C}$ for CPUs, while dissipating the base heat flux of $48.6 \mathrm{~W} / \mathrm{cm}^{2}$. The present tests did not attempt to approach the maximum heat dissipation (CHF) possible. As reported previously in the literature, the characteristic U-shape of heat transfer coefficient trend with the minimum located closer to the entrance of the channel was observed.

\section{ACKNOWLEDGMENTS}

This research is funded by the Nano-Tera RTD project CMOSAIC (ref. 123618) financed by the Swiss Confederation and scientifically evaluated by SNSF. The authors would like to thank the Microelectronic Systems Laboratory (LSM, EPFL) and Advanced Thermal Packaging group (IBM Zürich) for manufacturing the test sections and the workshop of the Heat and Mass Transfer Laboratory for the work done on the experimental facility. We wish to acknowledge Dr. Bogdan Alexandru Nichita for his assistance in the 3D Ansys FLUENT simulations. The authors wish to further thank Honeywell Inc. (Samuel Yana Motta) for providing the R1234ze(E) test fluid.

\section{REFERENCES}

[1] C.R. King, Jr., D. Sekar, M.S. Bakir, B. Dang, J. Pikarsky, and J.D. Meindl, "3D Stacking of Chips with Electrical and Microfluidic I/O Interconnects," Electronic Components and Technology Conference, 2008.

[2] B. Dang, M.S. Bakir, D.C. Sekar, C.R. King, Jr., and J.D. Meindl, "Integrated Microfluidic Cooling and Interconnects for 2D and 3D chips," IEEE Transactions on Advanced Packaging, vol. 33, no. 1, pp. 79-87, Feb. 2010.

[3] M.M. Sabry, A. Sridhar, D. Atienza, Y. Temiz, Y. Leblebici, S. Szczukiewicz, N. Borhani, J.R. Thome, T. Brunschwiler, and B. Michel, "Towards Thermallyaware Design of 3D MPSoCs with Inter-tier Cooling," Design, Automation and Test in Europe Conference, 2011.

[4] J. Marcinichen, J. Olivier, and J.R. Thome, "Reasons to Use Two-Phase Refrigerant Cooling," Electronics Cooling, 2011.

[5] G. Hetsroni, A. Mosyak, and Z. Segal, "Nonuniform Temperature Distribution in Electrical Devices Cooled by Flow in Parallel Microchannels," IEEE 
Transactions on Components and Packaging Technologies, vol. 24, pp. 16-23, 2001.

[6] J. Xu, S. Shen, Y. Gan, Y. Li, W. Zhang, and Q. Su, "Transient Flow Pattern Based Microscale Boiling Heat Transfer Mechanisms," Journal of Micromechanics and Microengineering, vol. 15, no. 6, pp. 1344-1361, 2005.

[7] H.Y. Wu and P. Cheng, "Visualization and Measurement of Periodic Boiling in Silicon Microchannels," International Journal of Heat and Mass Transfer, vol. 46, pp. 2603-2614, 2003.

[8] J.E. Park, J.R. Thome, and B. Michel, "Effect of Inlet Orifices on Saturated CHF and Flow Visualization in Multi-microchannel Heat Sink," $25^{\text {th }}$ IEEE SEMITHERM Symposium, 2009.

[9] F.P. Incropera, D.P. Dewitt, T.L. Bergman, and A.S. Lavine, Fundamentals of Heat and Mass Transfer, $6^{\text {th }}$ Edition, John \& Sons, 2007.

[10] F.M. White, Fluid mechanics, $4^{\text {th }}$ Edition, McGraw-Hill, 1999.

[11] R.K. Shah and A.L. London, Laminar Flow Forced Convection in Ducts, Academic Press, 1978.

[12] I.E. Idelcik, Memento des pertes de charge, 1999.

[13] E. Costa-Patry, J. Olivier, B.A. Nichita, B. Michel, and J. R. Thome, "Two-phase Flow of Refrigerant in $85 \mu \mathrm{m}$ - wide Multi-Microchannels: Part I - Pressure Drop," International Journal of Heat and Fluid Flow, vol. 32, pp. 451-463, 2011.

[14] H.R. Shanks, P.H. Sidles, P.D. Maycock, and G.C. Danielson, "Thermal Conductivity of Silicon from 300 to 1400 K," Physical Review, vol. 130, pp. 1743-1748, 1963.

[15] S.J. Kline and F.A. McClintock, "Describing Uncertainties in Single-Sample Experiments," Mechanical Engineering, vol. 75, pp. 3-8, 1953.

[16] C.L. Ong, "Macro-to-Microchannel Transition in TwoPhase Flow and Evaporation," Thesis No. 4674, Ph.D. thesis, École Polytechnique Fédérale de Lausanne, 2010.

[17] J.R. Thome, V. Dupont, and A.M. Jacobi, "Heat Transfer Model for Evaporation in Microchannels. Part I: Presentation of the Model," International Journal of Heat and Mass Transfer, vol. 47, pp. 3387-3401, 2004.

[18] N. Borhani, B. Agostini, and J.R. Thome, "A Novel Time Strip Flow Visualisation Technique for Investigation of Intermittent Dewetting and Dryout in Elongated Bubble Flow in a Microchannel Evaporator," International Journal of Heat and Mass Transfer, vol. 53, pp. 4809-4818, 2010. 